\title{
Effects of a Transactional Analysis Program on Adolescents' Emotion Regulation
}

\author{
Somaye Keshavarzi ${ }^{1}$, Eskandar Fathi Azar ${ }^{1}$, Mir Mahmoud Mirnasab ${ }^{1}$ \& Rahim Badri Gargari ${ }^{1}$ \\ ${ }^{1}$ Department of Education, Faculty of Education and Psychology, University of Tabriz, Tabriz, Iran \\ Correspondence: Somaye Keshavarzi, Department of Education, Faculty of Education and Psychology, \\ University of Tabriz, Tabriz, Iran. E-mail: keshavarzi.somaye@gmail.com
}

Received: September 11, 2016

Accepted: September 30, $2016 \quad$ Online Published: October 25, 2016

doi:10.5539/ijps.v8n4p51

URL: http://dx.doi.org/10.5539/ijps.v8n4p51

\begin{abstract}
Most adolescents are susceptible to exhibit emotional disorders due to rapid changes that occur during adolescence (Rudolph, 2002). To cope with such an issue, it is required to apply intervention programs in order to develop their competencies (Viner et al., 2012). In this study, the effect of transactional analysis on emotion regulation of 10th-grade female high school students has been examined by utilizing a quasi-experimental research (pre-test, post-test, and a control group design). Two classes have been chosen by cluster sampling and randomly assigned as the experimental and control groups. The Regulation of Emotion Questionnaire (Phillips \& power, 2007) was administrated. The transactional analysis program has been hold in eight sessions for the experimental group. Both groups were reexamined for follow-up a month later. The collected data were analyzed by Multivariate Analysis of Covariance (MANCOVA) indicates a significant increase in the functional emotion regulation strategies as well as a marked decrease in the dysfunctional emotion regulation strategies. The follow-up test also revealed an adequate stability. The implications of transactional analysis program will be discussed.
\end{abstract}

Keywords: adolescence, emotion regulation, transactional analysis

\section{Introduction}

\subsection{Emotional Development in Adolescents}

Emotional aspect is an essential component of adolescents' development. Some scholars believe that adolescents experience more negative emotions (such as stress, anxiety and depression) compared to their childhood (Newman, Moffitt, Caspi, Magdol, Silva, \& Stanton, 1996; Rudolph, 2002). Problems, conflicts, and negative emotions are a natural part of everyone's life; however, prolonged negative emotions can have a profound effect on physical and psychological health of an individual and impact his relationship with others (Diehl, Hay, \& Chui, 2012). Emotion regulation is a process comprised of recognition, monitoring, evaluation and modification of emotional reactions (Phillips \& Power, 2007). It is generally divided into functional (adaptive or healthy) and dysfunctional (maladaptive or unhealthy) strategies (Phillips \& Power, 2007; John \& Gross, 2004; Southam-Gerow \& Kendall, 2002). Functional emotion regulation is the ability to identify specific emotions and select the relevant strategy to regulate them (Eastbrook, 2013). Dysfunctional emotion regulation includes the strategies that reject or block emotional experiences and is recognized as a risk factor associated with emotional disorders such as anxiety and depression (Cole, Michel, \& Teti, 1994). Absence of functional strategies and also presence of dysfunctional strategies put individuals in a high emotional risk (Aldao, Jazaieri, Goldin, \& Gross, 2014; Phillips \& Power, 2007).

\subsection{Transactional Analysis Intervention}

According to the above findings, adolescents need special attention to develop their competencies. Intervention programs can improve their skills (Viner et al., 2012). Morris (2006) noted that adolescence is an opportune time to provide transactional analysis programs. TA was introduced by Berne in 1957. It is a theory concerning personal growth and also for improving interpersonal relationships (Riggall, Churches, \& Elwick, 2014; Morris, 2006). According to Berne, personality is made up of three ego states called Parent, Adult, and Child. Each ego state is recognized by a set of behaviors, thoughts, and feelings (Solomon, 2003). The Parent ego state is a set of behaviors, thoughts and feelings learned from parents or other characters. It can be divided to Nurturing and 
Critical Parents. The Adult ego state is the part of personality that processes data based on facts. The Child ego state is the part of personality based on the emotions and thoughts from childhood. It is broken down into Adapted and Natural (Free) Child (Solomon, 2003) (Figure 1).

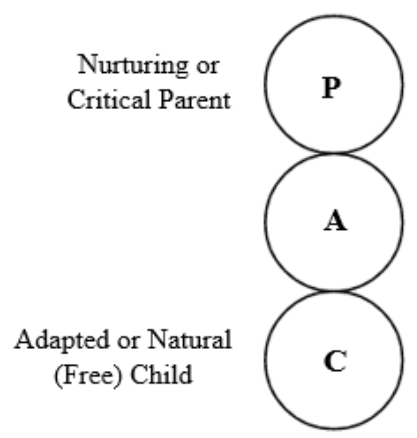

Figure 1. The ego state model

Transaction (another concept of TA) is defined as communications of people based on their ego state. It is divided to complementary, crossed, and ulterior components (Johnson, 2011; Solomon, 2003). In a complementary transaction, the communication between the initiator and the respondent are from the same ego state. As long as they remain in the same transactions, the communication may continue (Figure 2.1). In a crossed transaction a break occurs in the communication and may cause anger, frustration, or argument. In order to reestablish the communication, one or both of the individuals will need to shift their ego-states (Figure 2.2). In ulterior transaction, communication is based on a hidden meaning and can represent dishonest and unproductive communication (Johnsson, 2011; Solomon, 2003) (Figure 2.3).

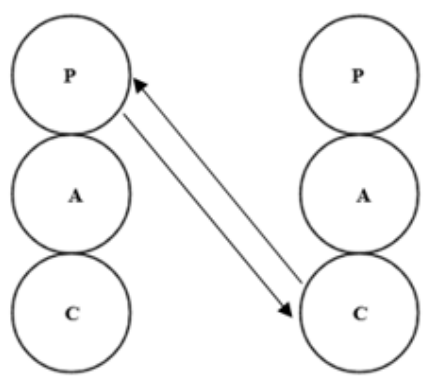

Figure 2.1

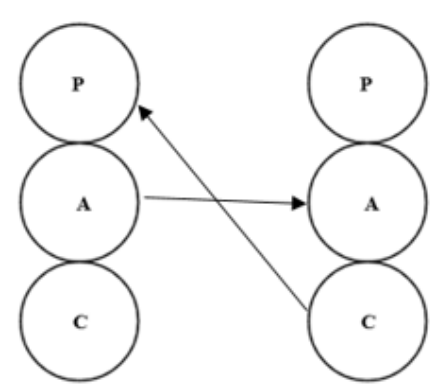

Figure 2.2

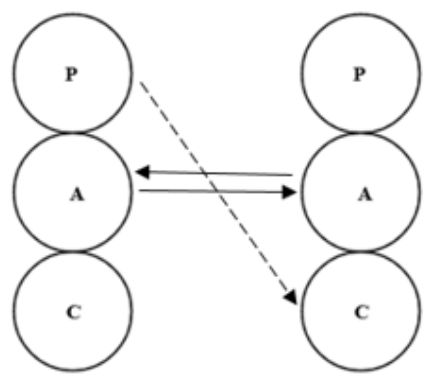

Figure 2.3

Figure 2. Transaction models

\subsection{Review of Literature}

So far, a lot of the transactional analysis studies have been executed on pathology (Chiesa, 2014; De Graaf \& Rosseau, 2015; Eusden \& Pierini, 2015; Tseng, Kawabata, Gau, \& Crick, 2014; Horn et al., 2015; Pierini, 2014; Van Rijn \& Wild, 2016). Transactional analysis was originally developed in psychotherapy; yet, it is deployed in education, counseling, and organizations (Corey, 2009; Morris, 2006; Vinella, 2013). Veiga (2004) and Emmerton and Newton (2004) stated that TA can be applied for the people with no clinical background. There are some studies that are devoted to the examination of TA in education (Barrow, 2007; Bastianelli, 2014; Hay \& Widén, 2015; McKimm \& Forrest, 2010; Morris, 2006; Newton \& Napper, 2007; Shotton, 2009; Stuart \& Alger, 2011). Helping students promote control over their actions, thoughts, and feelings and also acting more as an adult are important goals of transactional analysis in education (York, 2015; Veiga, 2004). There are also a dearth of empirical studies investigating the effect of TA in adolescence (Veiga, 2004; York, 2015). York (2015) developed a set of prevention and intervention programs (What's in Your Back Pack?) to assist secondary 
education students (9th, 10th, 11th, and 12th grades) in developing their communication skills and abilities in order to create changes in their behaviors. Findings revealed that the transactional analysis program can help adolescents make better decisions and reduce negative risk factors during their lifetime. Veiga (2004) carried out a transactional analysis intervention program around 18 school weeks on thirty-eight 8th-grade students in an experimental $(\mathrm{n}=17)$ and a control $(\mathrm{n}=21)$ group in Lisbon, Portugal. The TA program improved the high school students' behavioral adequacy in the experimental group compared with the control group. In brief, a lot of the TA studies were about pathology rather than development. In addition to lack of research in adolescents' development, there are also a lack of empirical studies investigated the effect of TA in adolescence. As such, we aimed to investigate the effect of transactional analysis training on emotion regulation strategies in adolescents.

\subsection{Hypotheses}

On the basis of literature review and the related theories, the following hypotheses were stated:

- Transactional analysis training increases the mean score of the functional strategies and decreases the mean score of the dysfunctional strategies in emotion regulation.

- Training transactional analysis has stability in the follow-up phase.

\section{Materials and Methods}

\subsection{Participants and Sampling Procedures}

The current study applied a quasi-experimental research design, with a pre-test, post-test and a control group. The population of this research is consisted of all the 10th-grade female high school students (16 year-old) in 2016 in Tabriz, Iran. The participants were chosen by multistage cluster random sampling method. The participants were selected from one of the five Educational Districts in the city of Tabriz. A school was randomly selected in this district. Then, two classes were selected from that school. The experimental and the control groups were 20 and 21 students respectively. The students who were absent more than a session or did not answer the questionnaire completely were omitted. Thus, each group consists of 19 students. Then they were randomly assigned to the experimental and the control groups. The pre-test was conducted one week before the intervention program for both the experimental and the control groups. The experimental group received 8 sessions of transactional analysis program (once a week, 90-minutes per session) and the control group did not receive any intervention. The post-test was performed one week after the last intervention session for both groups. Additionally, a follow-up test was carried out one month later to examine the lasting effects of TA training.

\subsection{Experimental Intervention}

The intervention program in this research was based on the pivotal tenets of transactional analysis, specifically the ego states and transaction. The researchers of this study designed the transactional analysis program grounded in Berne's theory and the findings of Morris (2006), Veiga (2004), and York (2015).

Table 1. A brief description of the TA intervention program sessions

\begin{tabular}{ll}
\hline Sessions & Contents \\
\hline Session 1 & $\begin{array}{l}\text { Establishing group rules-developing a contract to support the rules-discussing the goal of the program-performing Regulation } \\
\text { of Emotion Questionnaire (REQ) as the pre-test. }\end{array}$ \\
Session 2 & $\begin{array}{l}\text { Discussing about three types of ego state: Parent, Adult, Child (PCA)-discussing verbal and non-verbal cues (e.g., facial } \\
\text { expressions, body language, body temperature) to recognize ego states-giving some tasks* to the students to ascertain they are } \\
\text { able to distinguish different ego states. }\end{array}$ \\
Session 3 & $\begin{array}{l}\text { Overviewing the contents of the previous session-checking the students' homework regarding the ego states-discussing } \\
\text { different types of parents (Critical-Nurturing) and children (Adapted-Natural) ego state-training the students to draw egogram } \\
\text { (egogram helps students understand their personality according to their functional ego state). }\end{array}$ \\
Session 4 & $\begin{array}{l}\text { Overviewing the contents of the previous session-checking the students' homework regarding egogram-discussing structural } \\
\text { pathology (Contaminations and Exclusions). } \\
\text { Overviewing the contents of the previous session-checking the students' homework concerning structural } \\
\text { pathology-discussing the first type of transaction: complementary transaction-discussing the cons and pros of this kind of } \\
\text { transaction. } \\
\text { Overviewing the contents of the previous session-checking the students' homework concerning complementary }\end{array}$ \\
\hline
\end{tabular}


transaction-discussing the second type of transaction: crossed transaction-discussing the problems of using this type of transaction.

Session 7 Overviewing of the contents of the previous session-checking the students' homework concerning crossed transaction-discussing the third type of transaction: hidden transaction- discussing the problems of employing this transaction.

Session 8 Carrying out REQ tests as post-test-summing up the subjects presented during the course-answering the students' questions about the program-expressing gratitude to student for their participation.

\footnotetext{
"The tasks were related to the content of each session. For example the content of the second session was about "types of ego state". The students were asked to think back over the past 24 hours of their lives and write the thoughts and activities that they had. Then, they specified in which activities they acted like a child, their parents, or process data based on the facts.
}

\subsection{Instruments}

Regulation of Emotion questionnaire (REQ): this self-report questionnaire was developed and validated by Phillips and Power (2007) for adolescents aged 12 to 19. This inventory (with no total score) contains 19 items in 4 factors named internal-functional, external-functional, internal-dysfunctional and external-dysfunctional. Factor analysis was used for measuring the construct validity of REQ. Principle Components Analysis (PCA) with varimax rotation was performed. The Kaiser-Meyer-Olkin (KMO) measure of sampling adequacy was 0.59 , and Bartlett's test of sphericity was significant $\left(\chi^{2}(171)=260.56, \mathrm{P}<0.001\right)$. Items with factor loadings less than 0.3 were omitted (12 and 18). The result obtained two factors, called function $(1,3,4,6,8,9$, and 16) and dysfunction $(2,5,7,10,13,14,15,17$, and 19) that suggests a total of $35.85 \%$ of the variance in the data (see Table 2). Participants were asked to rate the items on 5-point Likert-type scales ranging from point one "not at all" to point five "always". Internal consistencies (alpha Cronbach's coefficients) for each strategy of function and dysfunction were 0.60 , and 0.81 , respectively.

Table 2. Factor analysis of items relating to emotion regulation

\begin{tabular}{|c|c|c|}
\hline Dimensions Items & Dysfunction & Function \\
\hline 17 & 0.77 & \\
\hline 5 & 0.74 & \\
\hline 19 & 0.74 & \\
\hline 10 & 0.69 & \\
\hline 2 & 0.67 & \\
\hline 15 & 0.62 & \\
\hline 14 & 0.60 & \\
\hline 13 & 0.42 & \\
\hline 7 & 0.36 & \\
\hline 9 & & 0.75 \\
\hline 3 & & 0.67 \\
\hline 4 & & 0.55 \\
\hline 8 & & 0.50 \\
\hline 11 & & 0.48 \\
\hline 1 & & 0.46 \\
\hline 6 & & 0.43 \\
\hline 16 & & 0.35 \\
\hline Initial Eigenvalues & 4.34 & 2.46 \\
\hline Extraction Sums of Squared Loading & 22.89 & 12.96 \\
\hline
\end{tabular}




\section{Result}

The means and standard deviations of the variables are presented in Table 3. The findings revealed that the mean score of the dysfunctional emotion regulation strategies decreased, while, the mean score of the functional emotion regulation strategies augmented in the experimental group from pre-test to post-test. It should be noted that there were just slight changes between the post-test and the follow-up.

Table 3. Means and standard deviations of the emotion regulation strategies in the experimental, control, and follow-up groups

\begin{tabular}{cccccccc}
\hline & & \multicolumn{2}{c}{ Pre-test } & \multicolumn{2}{c}{ Post-test } & \multicolumn{2}{c}{ Follow-up } \\
\cline { 3 - 7 } Strategies & & Experiment & Control & Experiment & Control & Experiment & Control \\
\hline Function & M & 31.05 & 32.05 & 35.42 & 32.94 & 35.57 & 32.63 \\
& SD & 3.15 & 2.75 & 2.89 & 3.71 & 4.50 & 3.56 \\
\multirow{2}{*}{ Dysfunction } & $\mathrm{M}$ & 27.57 & 27.36 & 22.57 & 26.36 & 23.15 & 26.94 \\
& $\mathrm{SD}$ & 5.93 & 7.25 & 4.23 & 4.47 & 5.50 & 4.41 \\
\hline
\end{tabular}

Before conducting the parametric test of multivariate analysis of covariance (MANCOVA) to test the hypotheses, tests of Box's M, and Levene's were used. According to Box's M test which was not significant $(\mathrm{P} \leq .001)$ for any variables, the assumption of homogeneity of covariance matrices $(\mathrm{P}=.60, \mathrm{~F}=.62$, Box $=1.98)$ was met.

Wilke's lambda test indicated that there was a significant difference between the experimental and the control groups considering at least one strategy of emotion regulation $\left(\mathrm{F}(2,33)=9.60, \mathrm{P}=.001\right.$, Wilk's $\Lambda=0.63, \eta_{\mathrm{p}}{ }^{2}=$ $0.37)$.

Levene's test was not significant for emotion regulation strategies (see Table 4). Thus, the assumption of equality of error variances was met.

Table 4. Levene's test of equality of error variances ${ }^{\mathrm{a}}$ dependent variable: emotion regulation

\begin{tabular}{lcccc}
\hline & F & df1 & df2 & Sig. \\
\hline Function & 1.04 & 1 & 36 & 0.32 \\
Dysfunction & 0.72 & 1 & 36 & 0.40 \\
\hline
\end{tabular}

Tests the null hypothesis that the error variance of the dependent variable is equal across groups.

a. Design: Intercept + pre-test + group

The results of multivariate analysis of covariance for emotion regulation strategies (see Table 5), revealed a significant decrease in the mean score of the dysfunctional emotion regulation strategy $(\mathrm{F}(1,34)=14.43, \mathrm{p}$ $\left.=.001, \eta_{\mathrm{p}}{ }^{2}=0.30\right)$, while, a significant increase was observed in the mean score of the functional emotion regulation strategy $\left(\mathrm{F}(1,34)=8.08, \mathrm{p}=.008, \eta_{\mathrm{p}}{ }^{2}=0.19\right)$ in the experimental group in comparison with the control group. In other words, transactional analysis had a positive effect on students' emotional competencies via decreasing the dysfunction and increasing the function strategies.

Table 5. The MANCOVA* of the means emotion regulation strategies in the experimental and control groups

\begin{tabular}{lcccccc}
\hline $\begin{array}{l}\text { Source of } \\
\text { variation }\end{array}$ & $\begin{array}{c}\text { Sum of } \\
\text { squares }\end{array}$ & Df & $\begin{array}{c}\text { Mean } \\
\text { square }\end{array}$ & F & $\begin{array}{c}\text { Sig. } \\
\text { Partial Eta } \\
\text { Square }\end{array}$ \\
\hline Function & 76.30 & 1 & 76.30 & 8.08 & 0.008 & 0.19 \\
Dysfunction & 146.22 & 1 & 146.22 & 14.43 & 0.001 & 0.30 \\
\hline
\end{tabular}

${ }^{*}$ MANCOVA: Multivariate Analysis of Covariance. 


\subsection{Follow-Up}

The results of MANCOVA for emotion regulation strategies (see Table 6), revealed a significant decrease in the mean score of the dysfunctional emotion regulation strategy $\left(\mathrm{F}(1,34)=5.03, \mathrm{p}=.03, \eta_{\mathrm{p}}{ }^{2}=0.13\right)$, while, a significant increase is noted in the mean score of the functional emotion regulation strategy $(\mathrm{F}(1,34)=5.50, \mathrm{p}$ $\left.=.02, \eta_{\mathrm{p}}{ }^{2}=0.14\right)$ in the experimental group in comparison with the control group.

Table 6. Results of covariance analysis the follow-up scores of emotion regulation strategy

\begin{tabular}{|c|c|c|c|c|c|c|}
\hline $\begin{array}{l}\text { Source of } \\
\text { variation }\end{array}$ & $\begin{array}{l}\text { Sum of } \\
\text { squares }\end{array}$ & Df & $\begin{array}{l}\text { Mean } \\
\text { square }\end{array}$ & $\mathrm{F}$ & Sig. & $\begin{array}{c}\text { Partial Eta } \\
\text { Square }\end{array}$ \\
\hline Function & 90.58 & 1 & 90.58 & 5.50 & 0.02 & 0.14 \\
\hline Dysfunction & 130.99 & 1 & 130.99 & 5.03 & 0.03 & 0.13 \\
\hline
\end{tabular}

The result of MANCOVA in the follow-up test revealed that transactional analysis intervention on female high school students had a fairly good stability after a month.

\section{Discussion}

We investigated the impact of the transactional analysis program on emotion regulation strategies among 10th-grade female high school students during 2016 in Tabriz, Iran. The findings of this contribution revealed that the transactional analysis program had a fairly logical effect on emotion regulation strategies. It should be noted that we found a fairly good stability in the follow-up test.

The findings revealed that the transactional analysis intervention initiated a significant decrease in the mean score of the dysfunctional emotion regulation strategies. In other words, maladaptive emotion regulation can be reduced by transactional analysis instruction. It is in line with the findings of Van Rijn and Wild (2016) and Widdowson (2012). Dysfunctional emotion regulation strategies reject or block emotional experiences and is considered as a risk factor associated with anxiety and depression (Cole, Michel, \& Teti, 1994). Aldao et al. (2007) also pointed out that dysfunctional emotion regulation strategies lead to a high emotional risk. Lack of awareness and understanding of emotions may cause problems and difficulties in emotion regulation (Buckholdt, Weiss, Young, \& Gratz, 2015; Gratz \& Roemer, 2004). Transactional analysis instruction can develop students' self-awareness (Van Rijn, Wild, Fowlie, Sills, \& van Beekum, 2011). Awareness, monitoring, and recognition of emotions allows individuals to modify the intensity and quality of their emotions (Gross, 1998). Furthermore, transactional analysis intervention can moderate emotional disorders such as anxiety (Van Rijn \& Wild, 2016; Van Rijn \& Wild, 2013; Widdowson, 2012).

The intervention also significantly increased the mean score of the functional emotion regulation strategies in the experimental group. It is congruent with the findings of Stuart and Alger (2011) and Morris (2006). Transactional analysis seems to be a valuable skill in functional emotion regulation. Functional emotion regulation strategies help individuals identify specific emotions and select the relevant strategy to regulate them (Eastbrook, 2013). Students with high transactional analysis skills have better self-awareness (Stuart \& Alger, 2011). Gratz and Roemer (2004) also focused on the importance of the awareness and understanding of emotions in functional emotion regulation. Barrow, Bradshaw and Newton (2001) and Morris (2006) mentioned that transactional analysis can be effective in the emotional well-being of students.

\section{Limitations}

There are a number of limitations that should be taken into account. In this study we had to choose both the experimental and the comparison groups from one school, therefore, the comparison group might have been aware of the program. Moreover, all schools in Iran are single-sex, therefore, the participants of this study were limited to female students.

\section{Suggestions for Further Research}

Although adolescents spend a large amount of their time with peers, the influence of their parents are undeniable. Future studies would benefit from teaching TA to parents. Moreover, this study was limited to female high school students. As a result, investigation of this research on male students can be conducted in future researches to examine the role gender differences on the obtained results. 


\section{Conclusions}

The findings revealed that transactional analysis instruction is important to empower adolescents' emotional skills. Such skills can help adolescents to evaluate, modify, and assert their emotions in an adaptive way. Findings of the study also allows adolescents to recognize and alter their ego state and transaction when it is needed. It can improve students' intrapersonal (self-awareness) and interpersonal (relationships with others) factors. It can also help students reduce negative risk factors in their lives.

\section{Acknowledgements}

The first author is grateful to Prof. Dr. Dietrich Albert \& Prof. Dr. Roswith Roth who provided insight that assisted the research.

\section{References}

Aldao, A., Jazaieri, H., Goldin, P. R., \& Gross, J. J. (2014). Adaptive and maladaptive emotion regulation strategies: Interactive effects during CBT for social anxiety disorder. Journal of Anxiety Disorders, 28, 382-389. http://dx.doi.org/10.1016/j.janxdis.2014.03.005

Barrow, G. (2007). Transactional analysis, pastoral care and education. Pastoral Care in Education, 25(1), 21-25. http://dx.doi.org/10.1111/j.1468-0122.2007.00396.x

Barrow, G., Bradshaw, E., \& Newton, T. (2001). Improving behavior and raising self-esteem in the classroom: A practical guide to using transactional analysis. London: David Fulton.

Bastianelli, L. (2014). An Italian team uses transactional analysis to help children in Brazil. Transactional Analysis Journal, 44, 87-95. http://dx.doi.org/10.1177/0362153714529089

Buckholdt, K. E., Weiss, N. H., Young, J., \& Gratz, K. L. (2015). Exposure to violence, posttraumatic stress symptoms, and borderline personality pathology among adolescents in residential psychiatric treatment: The influence of emotion dysregulation. Child Psychiatry \& Human Development, 46, 884-892. http://dx.doi.org/10.1007/s10578-014-0528-5

Chiesa, C. (2014). On the seashore of an endless world, children play: Using transactional analysis in play therapy with children. Transactional Analysis Journal, 44, 128-141. http://dx.doi.org/10.1177/0362153714539916

Cole, P. M., Michel, M. K., \& Teti, L. O. (1994). The development of emotion regulation and dysregulation: A clinical perspective. Monographs of the Society for Research in Child Development, 59(2-3), 73-100. http://dx.doi.org/10.2307/1166139

Corey, G. (2009). Transactional analysis. Retrieved from http://www.acadiau.ca/ rlehr/Transactional\%20Analysis\%20ch\%20Corey\%202013.pdf

De Graaf, A., \& Mil, R. (2015). Transactional analysis and conflict management: Embracing conflict as an opportunity for growth and learning. Transactional Analysis Journal, 45(4), 250-259. http://dx.doi.org/10.1177/0362153715606172

Diehl, M., Hay, E. L., \& Chui, H. (2012). Personal risk and resilience factors in the context of daily stress. Annual Review of Gerontology and Geriatrics, 32(1), 251-274. http://dx.doi.org/10.1891/0198-8794.32.251

Eastbrook, J. M. (2013). Emotional awareness and alexithymia: Emotional processing and regulation in adolescence (Doctoral dissertation). Queen's University, Kingston, Ontario, Canada. Retrieved from https://qspace.library.queensu.ca/bitstream/1974/8061/1/Eastabrook_Jennifer_M_201305_PHD.pdf

Emmerton, N., \& Newton, T. (2004). The journey of educational transactional analysis from its beginnings to the present. Transactional Analysis Journal, 34(3), 283-291.

Eusden, S., \& Pierini, A. (2015). Exploring contemporary views on therapeutic relating in transactional analysis game theory. Transactional Analysis Journal, 45(2), 128-140. http://dx.doi.org/10.1177/0362153715588300

Gratz, K. L., \& Roemer, L. (2004). Multidimensional assessment of emotion regulation and dysregulation: Development, factor structure, and initial validation of the difficulties in emotion regulation scale. Journal of Psychopathology and Behavioral Assessment, 26(1), 41-54. http://dx.doi.org/10.1023/B:JOBA.0000007455.08539.94

Gross, J. J. (1998). The emerging field of emotion regulation: An integrative review. Review of General Psychology, 2(3), 271-299. http://dx.doi.org/10.1037/1089-2680.2.3.271 
Hay, J., \& Widén, U. (2015). The Transactional analysis proficiency awards: A social action initiative. Transactional Analysis Journal, 45(3), 204-216. http://dx.doi.org/10.1177/0362153715601399

Horn, E. K., Verheul, R., Thunnissen, M., Delimon, J., Soons, M., Meerman, A. M., ... Busschbach, J. J. (2015). Effectiveness of short-term inpatient psychotherapy based on transactional analysis with patients with personality disorders: A matched control study using propensity score personality disorders. Journal of Personality Disorders, 29(5), 663-683. http://dx.doi.org/10.1521/pedi_2014_28_166

John, O. P., \& Gross, J. J. (2004). Healthy and unhealthy emotion regulation: Personality processes, individual differences, and lifespan development. Journal of Personality, 72(6), 1301-1334. http://dx.doi.org/10.1111/j.1467-6494.2004.00298.x

Johnsson, R. (2011). Transactional analysis psychotherapy: Three methods describing a transactional analysis group therapy (Doctoral dissertation). Retrieved from http://citeseerx.ist.psu.edu/viewdoc/download?doi=10.1.1.461.4838\&rep=rep1\&type=pdf

McKimm, J., \& Forrest, K. (2010). Using transactional analysis to improve clinical and educational supervision: The drama and winner's triangles. Postgraduate Medical Journal, 86, 261-265. http://dx.doi.org/10.1136/pgmj.2009.093310

Morris, G. L. (2006). Altered states: Using transactional analysis education to prevent conflict escalation and violence (Doctoral dissertation). Available from ProQuest Dissertations and Theses database.

Newman, D. L., Moffitt, T. E., Caspi, A., Magdol, L., Silva, P. A., \& Stanton, W. R. (1996). Psychiatric disorders in a birth cohort of young adults: Prevalence, comorbidity, clinical significance, and new case incidence from ages 11 to 21. Journal of Consulting and Clinical Psychology, 64, 552-562. http://dx.doi.org/10.1037/0022-006X.64.3.552

Newton, T., \& Napper, R. (2007). The bigger picture: Supervision as an educational framework for all fields. Transactional Analysis Journal, 37, 150-158.

Phillips, K. F. V., \& Power, M. J. (2007). A new self-report measure of emotion regulation in adolescents: The regulation of emotion questionnaire. Clinical Psychology and Psychotherapy, 14(2), 145-156. http://dx.doi.org/10.1002/cpp.523

Pierini, A. (2014). Being a transactional analysis child therapist: How working with children is different. Transactional Analysis Journal, 44, 103-117. http://dx.doi.org/10.1177/0362153714538937

Pinquart, M. (2009). Moderating effects of dispositional resilience on associations between hassles and psychological distress. Journal of Applied Developmental psychology, 30(1), 53-60. http://dx.doi.org/10.1016/j.appdev.2008.10.005

Riggall, A., Churches, R., \& Elwick, A. (2014). Action research for school improvement: Studies on able, gifted and talented learners, homework and white working-class pupils. CfBT Education Trust (online). Retrieved from http://files.eric.ed.gov/fulltext/ED546810.pdf

Rudolph, K. D. (2002). Gender differences in emotional responses to interpersonal stress during adolescence. Journal of Adolescent Health, 30, 3-13. http://dx.doi.org/10.1016/S1054-139X(01)00383-4

Shotton, P. (2009). Transactional analysis training, postmodernism, and education. Transactional Analysis Journal, 39(4), 293-297. http://dx.doi.org/10.1177/036215370903900404

Solomon, C. (2003). Transactional analysis theory: The basics. Transactional Analysis Journal, 33(1), 15-22. Retrieved from http://www.carolsolomonphd.com/web_pdfs/Transact.pdf

Southam-Gerow, M. A., \& Kendall, P. C. (2002). Emotion regulation and understanding. Implications for child psychopathology and therapy. Clinical Psychology Review, 22, 189-222. http://dx.doi.org/10.1016/S0272-7358(01)00087-3

Stuart, K., \& Alger, A. (2011). The use of transactional analysis in secondary education: A case study. Tean Journal, 3(1). Retrieved from http://194.81.189.19/ojs/index.php/TEAN/article/viewFile/89/163

Tseng, W., Kawabata, Y., Gau, S. S., \& Crick, N. R. (2014). Symptoms of attention-deficit/hyperactivity disorder and peer functioning: A transactional model of development. Journal of Abnormal Child Psychology, 42(8), 1353-1365. http://dx.doi.org/10.1007/s10802-014-9883-8 
Van Rijn, B., \& Wild, C. (2013). Humanistic and integrative therapies for anxiety and depression: Practicebased evaluation of transactional analysis, gestalt, and integrative psychotherapies and person-centered counseling. Transactional Analysis Journal, 43, 150-163. http://dx.doi.org/10.1177/0362153713499545

Van Rijn, B., \& Wild, C. (2016). Comparison of transactional analysis group and individual psychotherapy in the treatment of depression and anxiety. Transactional Analysis Journal, 46(1), 63-74. http://dx.doi.org/10.1177/0362153715615115

Van Rijn, B., Wild, C., Fowlie, H., Sills, C., \& Van Beekum, S. (2011). Impact of transactional analysis psychotherapy training on self-awareness and ability for contact. International Journal of Transactional Analysis Research, 1(2), 3-11. Retrieved from http://www.acissydney.com.au/uploads/2/5/0/0/25007734/2010_research_artikel_ijtar.pdf

Veiga, F. H. (2004). Promotion of rights and behavioral adequacy of students in school: Effects of a transactional analysis program. Paper presented at the XXVth International School Psychology Colloquium-News: School Psychology: Whose needs? Whose benefit?

Vinella, P. (2013). Transactional analysis counseling groups: Theory, practice, and how they differ from other TA groups. Transactional Analysis Journal, 43(1), 68-79. http://dx.doi.org/10.1177/0362153713486111

Viner, R. M., Ozer, E. M., Denny, S., Marmot, M., Resnick, M., Fatusi, A., \& Currie, C. (2012). Adolescence and the social determinants of health. The Lancet, 379(9826), 1641-1652. http://dx.doi.org/10.1016/S0140-6736(12)60149-4

Widdowson, M. D. J. (2013). The process and outcome of transactional analysis psychotherapy for the treatment of depression: An adjudicated case series (Doctoral dissertation). Retrieved from https://lra.le.ac.uk/bitstream/2381/28382/1/2013WIDDOWSONMDJPhD.pdf

York, B. E. (2015). What's in your back pack? Validation of a transactional analysis intervention program Southwestern college (Doctoral dissertation). Available from ProQuest Dissertations and Theses database.

\section{Copyrights}

Copyright for this article is retained by the author(s), with first publication rights granted to the journal.

This is an open-access article distributed under the terms and conditions of the Creative Commons Attribution license (http://creativecommons.org/licenses/by/4.0/). 